\title{
The Solidification Time of Cylindrical Sand Mold Castings of Various Metals Affected by the Decrease in Surface Temperature*
}

\section{By Eisuke NIYAMA**}

\section{Synopsis}

Validity of the assumption of constant surface temperature in Choorinov's and Adams' equations for the solidification time of castings was examined by numerical calculations. In the case of metals having high heat diffusivity like copper or aluminum, the decrease in surface temperature during solidification is negligible and Adams' equation can satisfactorily be used without correction, while Chvorinov's equation gives excessively large solidification time for cylinders. In the case of metals with low heat diffusivity like iron or lead, the decrease in surface temperature in cylinder is so large that corrections are necessary for Adams' equation. In such a case, Chvorinov's equation often gives a better approximation than Adams', if no corrections are made. A formula was proposed to predict the temperature drop in a given combination of metal and mold and to correct the figures to be used in Adams' equation. With these corrections, Adams' equation can consistently be a most reliable method to estimate the solidification time of a casting in sand mold.

\section{Introduction}

Chvorinov's equation ${ }^{1)}$ has been widely used to estimate the solidification time of sand mold castings. Although the details of solidification profiles can be predicted with the aid of computer which is extensively used in the present, this equation can still be valuable for the daily casting designing.

In order to improve the precision of the equation, some attempts have been made from both experimental ${ }^{2)}$ and theoretical stand points. ${ }^{3)}$ The purpose of the present work is to further improve the precision by considering the change in the surface temperature of a casting during solidification, which has so far been assumed to be constant.

According to Chvorinov, the solidification time of a casting is

$$
\begin{aligned}
t_{f} & =\frac{1}{q^{2}}(V / A)^{2} \\
& =K(V / A)^{2} .
\end{aligned}
$$

The symbols used throughout this work are listed in Table 1. In the above equation, $q$ is the solidification constant to give the thickness of the solidified layer $X$.

$$
X=q \sqrt{ } t
$$

Assuming that the surface temperature of mold $\theta_{i}$ is constant, $q$ for a plate casting is

$$
q=2 b_{1}\left(\theta_{i}-\theta_{1}\right) / \sqrt{ } \pi \rho_{2} L
$$

If there is superheat $\Delta \theta, L$ may be replaced with

\begin{tabular}{|c|c|c|}
\hline$\theta$ & Temperature & ${ }^{\circ} \mathrm{C}$ \\
\hline$\theta_{f}$ & Solidification temperature (mp) & ${ }^{\circ} \mathrm{C}$ \\
\hline$\theta_{c}$ & Casting temperature & ${ }^{\circ} \mathrm{C}$ \\
\hline$\theta_{1}$ & Initial temperature of mold & ${ }^{\circ} \mathrm{C}$ \\
\hline$\theta_{i}$ & $\begin{array}{l}\text { Interface temperature between metal } \\
\text { and mold }\end{array}$ & ${ }^{\circ} \mathrm{C}$ \\
\hline$\theta_{e}$ & $\theta_{i}$ when solidification ends at center & ${ }^{\circ} \mathrm{C}$ \\
\hline$\theta_{a}$ & $\begin{array}{l}\text { Average temperature of casting when } \\
\text { solidification ends at center }\end{array}$ & ${ }^{\circ} \mathrm{C}$ \\
\hline$\prime_{m}$ & $\begin{array}{l}\text { Mean effective } \theta_{i} \text { during solidifica- } \\
\text { tion }\end{array}$ & ${ }^{\circ} \mathrm{C}$ \\
\hline$t$ & Time & sec \\
\hline$t_{f}$ & Solidification time & $\sec$ \\
\hline$L$ & Latent heat of solidification & $\mathrm{cal} / \mathrm{g}$ \\
\hline$k_{1}, k_{2}$ & Thermal conductivity & $\mathrm{cal} / \mathrm{cm} \mathrm{sec} \mathrm{deg}$ \\
\hline$\rho_{1}, \rho_{2}$ & Density & $\mathrm{g} / \mathrm{cm}^{3}$ \\
\hline$c_{1}, c_{2}$ & Specific heat & $\mathrm{cal} / \mathrm{g} \mathrm{deg}$ \\
\hline$\alpha_{1}, \alpha_{2}$ & Temperature diffusivity $(k / \rho c)$ & $\mathrm{cm}^{2} / \mathrm{sec}$ \\
\hline$b_{1}, b_{2}$ & Heat diffusivity $(\sqrt{ } k \rho c)$ & $\mathrm{cal} / \mathrm{cm}^{2} \mathrm{deg} \mathrm{sec} \sec ^{1 / 2}$ \\
\hline$q$ & Solidification constant & $\mathrm{cm} / \mathrm{sec}^{1 / 2}$ \\
\hline$\kappa$ & Chvorinov's constant & $\mathrm{sec} / \mathrm{cm}^{2}$ \\
\hline$V$ & Casting volume & $\mathrm{cm}^{3}$ \\
\hline$A$ & Casting surface area & $\mathrm{cm}^{2}$ \\
\hline$X$ & Thickness of solidified layer & $\mathrm{cm}$ \\
\hline$P$ & Adams' correction factor & \\
\hline$T^{*}$ & $\begin{array}{l}\text { Relative surface temperature } \\
\quad\left(\theta_{e}-\theta_{1}\right) /\left(\theta_{f}-\theta_{1}\right)\end{array}$ & \\
\hline$A^{*}$ & Relative temperature diffusivity $\alpha_{1} / \alpha_{2}$ & \\
\hline$B^{*}$ & Relative heat diffusivity $b_{1} / b_{2}$ & \\
\hline$L^{*}$ & Relative latent heat $L / c_{2}\left(\theta_{f}-\theta_{1}\right)$ & \\
\hline Suffix & 1 for mold, 2 for metal & \\
\hline
\end{tabular}
$L+c_{2} \Delta \theta$. Chvorinov found experimentally on steel castings that a single value of $q$ or $K$ can commonly
Table 1. Symbols

be used for plates, cylinders and other shapes.

Adams showed theoretically that $q$ must be a function of the geometrical shape of the casting. For a plate, Eq. (4) can be used. For a cylinder, the modified $q$ is

$$
\begin{aligned}
& q= {\left[2 b_{1}\left(\theta_{i}-\theta_{1}\right) / \sqrt{ } \pi \rho_{2}\left\{L+c_{2}\left(\theta_{c}-\theta_{j}\right)\right\}\right] } \\
&\left(\frac{1+\sqrt{ } 1+P}{2}\right) \\
& 2
\end{aligned}
$$

where,

$$
P=\pi \rho_{2}\left\{L+c_{2}\left(\theta_{c}-\theta_{f}\right)\right\} / 4 \rho_{1} c_{1}\left(\theta_{i}-\theta_{1}\right)
$$

The term of $P$ is introduced to cover the 'corner' effect, that is, heat diffuses in increasingly wider space in the mold as the distance from the casting surface increases.

* Received April 21, 1971.

** Hitachi Research Laboratory, Katsuta Works, Hitachi Ltd., Katsuta 312. 
The measurement made by Adams on aluminum, copper, and tin cast in sand showed a close agreement with the theory. Here again $\theta_{i}$ is assumed to be constant and, in fact, it was found to be experimentally equal to the melting point of the metals within $10^{\circ} \mathrm{C}$. According to Adams' equation, the solidification time of a cylinder or a sphere must be as much as $30 \%$ less than that of a plate having the same ratio of volume to surface area. However, the difference found by Chvorinov on steel castings was at most 10\%. According to Pellini, ${ }^{2)}$ the solidification time of a steel bar, which can be regarded geometrically quite similar to a cylinder, is even larger than that of a plate by about $20 \%$. It will be shown in the following discussion that all of these contradictions can be interpreted with Adams' equation by considering the decrease in surface temperature during solidification.

\section{Numerical Calculations}

Because of the difficulty associated with the exact analytical treatment, a numerical method was adopted to examine the solidification time and the change in the surface temperature of castings of various metals. The forward difference method, essentially that of Dusinberre, ${ }^{5)}$ was used. Cylindrical castings of $20 \mathrm{~cm}$ in diameter were concentrically sectioned in 5 to 10 sections. The molds were so thick as to be regarded as infinite and were sectioned in 20 to 25 sections. Perfect contact was assumed to be realized between casting and mold. The longitudinal heat flow was neglected. In this method, only pure metals were considered and the specific heat of the metal was raised in a narrow solidification range, for example $0.1^{\circ} \mathrm{C}$, just below the melting point by an amount corresponding to the latent heat of solidification. Pouring temperature was assumed to be equal to the melting point, i.e. there is no superheat. It was also assumed that the initial temperature of the mold was $0^{\circ} \mathrm{C}$. Thermal properties of the materials were as- sumed to be constant and are listed in Table 2. These values were quoted from the book by Ruddle ${ }^{4}$ and are only approximate, and thus the results obtained are not highly quantitative in nature. Besides the realistic values simulating real metals and mold materials, various combinations of hypothetical values were used in the calculation for the sake of comparison. Calculations were made on metallic molds as well as sand molds.

\section{Numerical Results on Typical Castings}

The calculated results for pure iron poured in cylindrical and plane sand molds are shown in Fig. 1. The surface temperature of the cylindrical casting in the moment of the end of solidification at the center is $1403^{\circ} \mathrm{C}$. The decrease in surface temperature is $97^{\circ} \mathrm{C}$ and is by no means small. This fact indicates that before the end of solidification, the mold must have absorbed not only the latent heat of solidification but also the heat corresponding to this temperature drop. More precisely, the average temperature of the whole section of the casting at the end of solidifica-

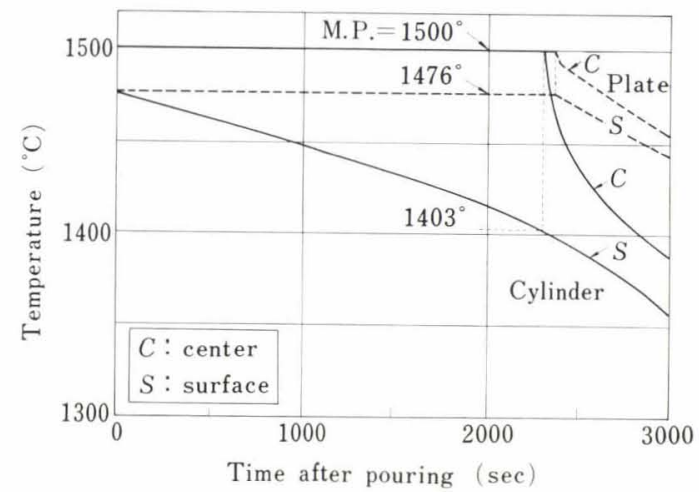

Fig. 1. Results of numerical calculation on the temperatures at center and surface of iron plate and cylinder cast in sand molds. Thermal properties are listed in Table 2. Sand C.

Table 2. Thermal properties

\begin{tabular}{|c|c|c|c|c|c|c|c|}
\hline & $\theta_{f}$ & $L$ & c & $\rho$ & $k$ & $\alpha$ & $b$ \\
\hline $\mathrm{Bi}$ & 270 & 11.2 & 0.03 & 9.8 & 0.02 & 0.068 & 0.0767 \\
\hline $\mathrm{Pb}$ & 327 & 5.9 & 0.03 & 11.3 & 0.08 & 0.214 & 0.173 \\
\hline $\mathrm{Sn}$ & 232 & 14.5 & 0.06 & 7.3 & 0.15 & 0.343 & 0.256 \\
\hline $\mathrm{Fe}$ & $1500 *$ & 65.0 & 0.20 & 7.5 & 0.10 & 0.067 & 0.388 \\
\hline $\mathrm{Ni}$ & 1455 & 71.7 & 0.15 & 8.9 & 0.15 & 0.112 & 0.448 \\
\hline $\mathrm{Zn}$ & 420 & 27.0 & 0.10 & 7.1 & 0.25 & 0.352 & 0.421 \\
\hline $\mathrm{Al}$ & 660 & 95.3 & 0.26 & 2.7 & 0.50 & 0.712 & 0.593 \\
\hline $\mathrm{Cu}$ & 1083 & 49.1 & 0.12 & 8.9 & 0.90 & 0.843 & 0.981 \\
\hline Hypothetical metals & 1000 & $0.02 / 100$ & $0.1 / 0.2$ & $0.1 / 30$ & $10^{-5} / 100$ & $10^{-5} / 100$ & $10^{-4} / 10$ \\
\hline Sand mold** A & 一 & - & 0.20 & 1.7 & 0.0015 & 0.0044 & 0.023 \\
\hline Sand mold & - & - & 0.20 & 1.7 & 0.0020 & 0.0059 & 0.026 \\
\hline Sand mold D & - & - & 0.15 & 3.0 & 0.0050 & 0.0111 & 0.047 \\
\hline Hypothetical molds & - & - & $0.1 / 0.5$ & $1 / 10$ & $10^{-3} / 0.2$ & $0.01 / 0.1$ & $0.01 / 0.1$ \\
\hline
\end{tabular}

* A low solidification temperature was used for iron to simulate steel.

** Sand A, B, C, and D simulate silica at low, medium, and high temperature and zircon sand, respectively. 
tion is calculated to be $1428^{\circ} \mathrm{C}$. Hence, the average temperature drop is $1500^{\circ}-1428^{\circ}=72^{\circ} \mathrm{C}$ and the heat to be absorbed is $L+c_{2} \Delta \theta=65+0.2 \times 72=79.4$ $\mathrm{cal} / \mathrm{g}$.

Rate of heat absorption by the mold, on the other hand, is governed by the surface temperature of the mold $\theta_{i}$ as already mentioned in Eq. (5). Since $\theta_{i}$ changes from $1500^{\circ}$ to $1403^{\circ} \mathrm{C}$ during solidification, the effective mean surface temperature of the mold could not be $1500^{\circ} \mathrm{C}$ but must lie between $1500^{\circ}$ and $1403^{\circ} \mathrm{C}$, the simplest estimate being the arithmetic mean of the two, $1452^{\circ} \mathrm{C}$.

Thus, two corrections are necessary, if the solidification time of a cylinder is estimated by Adams' equation; the correction for the heat absorbed before the end of solidification and the correction for the surface temperature of the mold. Both corrections will tend to increase the estimate of solidification time. The solidification times calculated from Chvorinov's and Adams' equations with and without these corrections are listed in Table 3. Necessary figures for the corrections were obtained from the numerical results.

Let us regard the result of numerical method which is considered most accurate as the standard value. The solidification time calculated from Chvorinov's equation is $88 \%$ of the standard value. The value obtained from Adams' equation without any corrections is, as expected, much smaller and is only $63 \%$ of the standard, which is improved up to $92 \%$ by the introduction of the correction for the heat absorbed and up to $97 \%$ by the corrections for both the heat absorbed and the mold temperature. From this fact, it is obvious that these corrections, particularly the correction for the heat absorbed are very important.

By comparing the numerical results, the solidification time for a cylinder is $98 \%$ of that for a plate. This means that the constant $K$ of Eq. (2) for a plate differs by only $2 \%$ from that for a cylinder. It is found from the foregoing that such a precision is accidentally obtained due to the mutual cancelling of two inaccurate assumptions, namely, the neglect of corner effect and the assumption of constant surface temperature.

On a plate casting, Chvorinov's value is $86 \%$ of the standard. The surface temperature is constant during solidification but is lower than the melting point by $24^{\circ} \mathrm{C}$. If two corrections are similary made on Eq. (4), the value is improved up to $94 \%$. Since the improvement is small for the plate casting, the correction may be omitted in most cases.

Figure 2 shows that the decrease in the surface temperature of copper cast in sand is as small as $7^{\circ} \mathrm{C}$ even in the case of a cylinder. It is seen from Table 3 that Adams' equation without correction gives a quite satisfactory value for copper, while Chvorinov's value is much larger than that.

Generalizing the above results, it may be said that Adams' equation, instead of Chvorinov's, should be applied to those cylindrical castings whose decrease in surface temperature during solidification is small. However, at least, correction for the heat absorbed
Table 3. Effect of various corrections on the calculated solidification times of iron and copper

$$
t_{f} \text { by Eq. (5) (Adams) }
$$

\begin{tabular}{|c|c|c|c|c|c|}
\hline & \multirow{2}{*}{$\begin{array}{c}t_{f} \text { by } \\
\text { Eq. (4) } \\
\text { (Chvorinov) }\end{array}$} & \multicolumn{3}{|c|}{ Correction of temp. drop } & \multirow{2}{*}{$\begin{array}{c}t_{f} \text { by } \\
\text { numerical } \\
\text { solution }\end{array}$} \\
\hline & & No & Heat & $\begin{array}{l}\text { Heat \& } \\
\text { mold } \\
\text { temp. }\end{array}$ & \\
\hline $\begin{array}{l}\text { Iron } \\
\text { cylinder }\end{array}$ & $\begin{array}{c}2024 \\
(88 \%)\end{array}$ & $\begin{array}{c}1450 \\
(63 \%)\end{array}$ & $\begin{array}{c}2125 \\
(92 \%)\end{array}$ & $\begin{array}{l}2247 \\
(97 \%)\end{array}$ & $\begin{array}{c}2310 \\
(100 \%)\end{array}$ \\
\hline $\begin{array}{l}\text { Copper } \\
\text { cylinder }\end{array}$ & $\begin{array}{c}4692 \\
(139 \%)\end{array}$ & $\begin{array}{c}3285 \\
(97 \%)\end{array}$ & $\begin{array}{c}3341 \\
(99 \%)\end{array}$ & $\begin{array}{l}3358 \\
(99 \%)\end{array}$ & $\begin{array}{c}3380 \\
(100 \%)\end{array}$ \\
\hline $\begin{array}{l}\text { Iron } \\
\text { plate }\end{array}$ & $\begin{array}{l}2024 \\
(86 \%)\end{array}$ & & & $\begin{array}{l}2211 * \\
(94 \%)\end{array}$ & $\begin{array}{c}2350 \\
(100 \%)\end{array}$ \\
\hline
\end{tabular}

* Correction on plate was made by Eq. (4).

* Cylinder diameter $20 \mathrm{~cm}$ and plate thickness $10 \mathrm{~cm}$. Thermal properties from Table 2, Sand B for copper and sand C for iron.

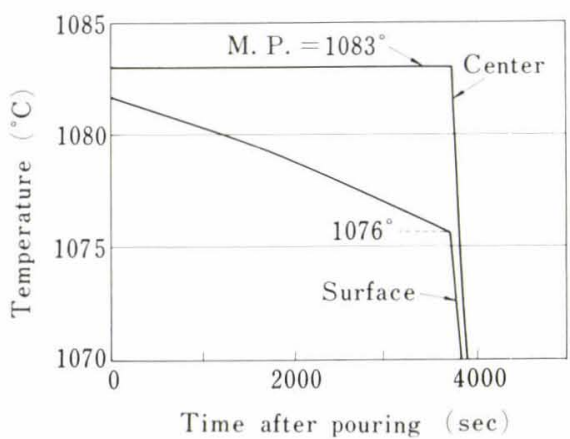

Fig. 2. Result of numerical calculation on the temperatures at center and surface of copper cylinder cast in sand mold. Thermal properties are listed in Table 2. Sand B.

is necessary when Adams' equation is applied to those cylindrical castings whose decrease in surface temperature is large. In the case of sand cast steel, two neglected factors in a cylinder fortunately cancel out each other to give a value of constant $K$ nearly equal to that of a plate.

\section{Analytical Considerations}

Recognizing the importance of the decrease in surface temperature during solidification, it would be worth-while to find the factors governing that amount. Although the exact solution can hardly be obtained, some analytical consideration may be necessary as a guide for the later numerical approach.

Assuming the metal and mold as semi-infinitely thick plates and neglecting the heat of solidification, the interface temperature is constant, independent of the time, and is given by the following formula. ${ }^{6)}$

$$
\theta_{i}=\frac{b_{1} \theta_{1}+b_{2} \theta_{c}}{b_{1}+b_{2}}
$$

Using the above equation and the values listed in Table 2, $\theta_{i}$ for iron and sand $\mathrm{C}$ becomes $1386^{\circ} \mathrm{C}$. If the latent heat of solidification of the metal is considered, $b_{1}$ in Eq. (7) must be replaced with $b^{\prime}$ defined as $^{71}$

$$
b^{\prime}=b_{1} \operatorname{erf}\left(q / \sqrt{ } \alpha_{2}\right)
$$


where, $q$ is the solidification constant used in Eq. (3) and is obtained by solving Schwarz's equation, not shown here, with successive approximation. Since this procedure is rather tedious, a simplified form is proposed here. By assuming that the surface temperature is constant for a plate casting and by considering the heat transfer within the casting alone, $q$ is approximately given by Stefan's equation. ${ }^{\text {i) }}$

$$
q \doteqdot \sqrt{ } 2 k_{2}\left(\theta_{f}-\theta_{i}\right) / \rho_{2} L
$$

On the other hand, assuming also a constant surface temperature and considering the heat transfer within the mold alone, $q$ is given by $\mathrm{Eq}$. (4). The value of $\theta_{i}$ is obtained by combining the two together. When $\theta_{f} b_{1}^{2} / k_{2} \rho_{2} L$ is sufficiently small, the approximate solution can be written as

$$
\theta_{i} \fallingdotseq \theta_{1}+\left(\theta_{f}-\theta_{1}\right)\left\{\begin{array}{c}
2 b_{1}^{2}\left(\theta_{j}-\theta_{1}\right) \\
\pi k_{2} \rho_{2} L
\end{array}\right\}
$$

This may be regarded as an approximation of Schwarz's method. For iron poured in sand C mentioned in Table 2, the approximate $\theta_{i}$ by Eq. (10) is $1469^{\circ} \mathrm{C}$ and the exact $\theta_{i}$ by Eqs. (7) and (8) is $1472^{\circ} \mathrm{C}$. The numerical result on a plate shown in Fig. 1 also indicates a constant surface temperature, despite of the finite thickness. This can be expected only when superheat is zero degrees. The value of $1476^{\circ} \mathrm{C}$ is also nearly equal to the exact solution for a semiinfinite plate.

The surface temperature of a cylinder as calculated numerically (Fig. 1) starts from the same value as the above mentioned and decreases gradually. This is reasonable, since the cylindrical interface may be regarded as a plane in the initial stage of cooling and the effect of geometry, or 'corner' effect, becomes gradually apparent as the rate of heat absorption by the mold relative to the rate of heat generation from the casting increases with time. The surface temperature at the end of solidification is $1403^{\circ} \mathrm{C}$ and much lower than the starting temperature. It is rather near the value given by Eq. (7).

Since two factors, namely, the latent heat and the cylindrical shape, are neglected in Eq. (7), there is no direct reason why the surface temperature at the end of solidification of a cylinder must be near that value. Yet, it may serve as a guide in seeking a simplified expression for the temperature drop, when there is no exact solution available for this purpose.

\section{Factors Governing the Decrease in Surface Temperature}

The physical situation suggests that the major factors involved in the present problem are $k_{1}, k_{2}, c_{1}$, $c_{2}, \rho_{1}, \rho_{2}, L, \theta_{f}-\theta_{1}$ and $\theta_{e}-\theta_{1}$. Introducing the $\pi$ theorem, ${ }^{8)}$ four dimension-less products $T^{*}, A^{*}, B^{*}$ and $L^{*}$ were formulated. As explained in Table 1, $T^{*}$ is the relative surface temperature at the end of solidification, $A^{*}$ the relative temperature diffusivity, $B^{*}$ the relative heat diffusivity, and $L^{*}$ the relative latent heat of solidification. Now the aim is to find the actual form of the following relationship.

$$
T^{*}=F\left(A^{*}, B^{*}, L^{*}\right)
$$

Using these dimensionless variables and $\theta_{i}$ for $\theta_{\epsilon}$, Eq. (7) can be rewritten as

$$
T^{*}=1 /\left(1+B^{*}\right)
$$

and Eq. (10) as

$$
T *=1-\left(2 B^{* 2} / \pi L^{*}\right)
$$

About one hundred numerical " experiments" were made with the aid of a computer and the relative surface temperature $T^{*}$ thus obtained were plotted against various combinations of $A^{*}, B^{*}$, and $L^{*}$. Figure 3 is the plot suggested from Eq. (12). The agreement is fair, considering the wide range of $B^{*}$ and $T^{*}$. This means that the relative error of $\theta$, by Eq. (12) is small as compared with the numerical solution. However, when the decrease in surface temperature $\theta_{f}-\theta_{e}$, instead of temperature $\theta_{e}$ is taken into account, the relative error is still considerable as indicated in Table 4. It was noticed that the error was particularly large in the case of metals whose $A^{*} / L^{*}$ was large. Thus, another expression was tried and is plotted in Fig. 4.

$$
T^{*}=\frac{1}{1+B^{* 4} \sqrt{A^{*} / L^{*}}}
$$

The reduction in scatter of plotted values in Fig. 4 as compared with Fig. 3 is not so great. But, if this application is limited to real metals cast in sand, the error of $\theta_{f}-\theta_{e}$ is sufficiently small, as shown in Table 4. Trials based on Eq. (13) were not successful.

It is concluded that the decrease in surface temperature is mainly governed by the relative heat diffusivity $B^{*}$ and Eq. (7) or (12) may be used for a rough estimate. In order to obtain a greater precision, the relative temperature diffusivity $A^{*}$ and the relative latent heat of solidification $L^{*}$ must be taken into consideration. Equation (14) is an empirical and

Table 4. Estimation of the decrease in surface temperature

\begin{tabular}{c|c|ccc|rrrr}
\hline $\begin{array}{c}\text { Met- } \\
\text { al }\end{array}$ & Mold & $A^{*}$ & $B^{*}$ & $L^{*}$ & $\begin{array}{r}\text { From } \\
\text { Eq. } \\
(12)\end{array}$ & $\begin{array}{c}\text { From } \\
\text { Eq. } \\
(14)\end{array}$ & $\begin{array}{c}\text { Numeri- } \\
\text { cal } \\
\text { solution }\end{array}$ \\
\hline & & & & & & & & \\
\hline $\mathrm{Bi}$ & Sand A & 0.0650 & 0.295 & 1.383 & 62 & 33 & 40 \\
$\mathrm{~Pb}$ & Sand A & 0.0206 & 0.130 & 0.547 & 38 & 18 & 21 \\
$\mathrm{Fe}$ & Sand D & 0.169 & 0.122 & 0.217 & 163 & 155 & 150 \\
$\mathrm{Sn}$ & Sand A & 0.0129 & 0.088 & 1.042 & 19 & 7 & 7 \\
$\mathrm{Fe}$ & Sand C & 0.132 & 0.083 & 0.217 & 116 & 102 & 97 \\
$\mathrm{Ni}$ & Sand C & 0.0785 & 0.071 & 0.329 & 97 & 69 & 60 \\
$\mathrm{Mg}$ & Sand A & 0.0075 & 0.058 & 0.455 & 36 & 13 & 13 \\
$\mathrm{Zn}$ & Sand A & 0.0125 & 0.054 & 0.643 & 21 & 8 & 6 \\
$\mathrm{Al}$ & Sand A & 0.0062 & 0.038 & 0.555 & 23 & 8 & 8 \\
$\mathrm{Cu}$ & Sand B & 0.0070 & 0.027 & 0.378 & 23 & 11 & 7 \\
\hline $\mathrm{Pb}$ & Iron mold & 0.308 & 2.24 & 0.547 & 226 & 216 & 235 \\
$\mathrm{Fe}$ & Iron mold & 1.0 & 1.0 & 0.217 & 750 & 891 & 861 \\
$\mathrm{Al}$ & Iron mold & 0.0927 & 0.655 & 0.555 & 261 & 195 & 250 \\
$\mathrm{Cu}$ & Iron mold & 0.0784 & 0.395 & 0.378 & 307 & 228 & 293 \\
& & & & & & & \\
\hline
\end{tabular}




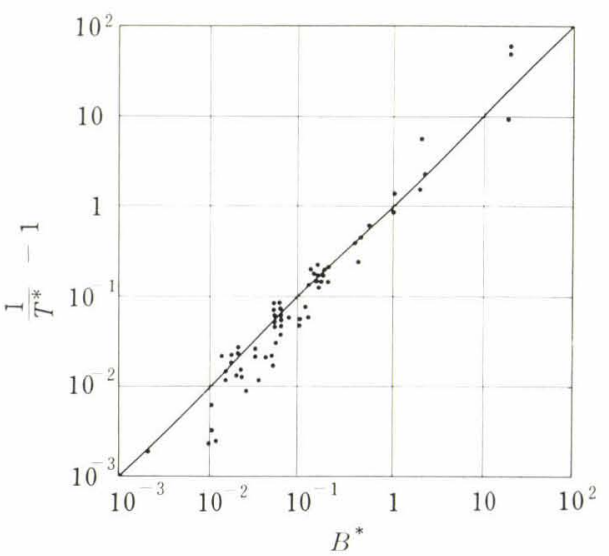

Fig. 3. The relation between the relative surface temperature $T^{t}=\left(\theta_{e}-\theta_{1}\right) /\left(\theta_{f}-\theta_{1}\right)$ and the relative heat diffusivity $B^{*}=b_{1} / b_{2}$ obtained from numerical calculations

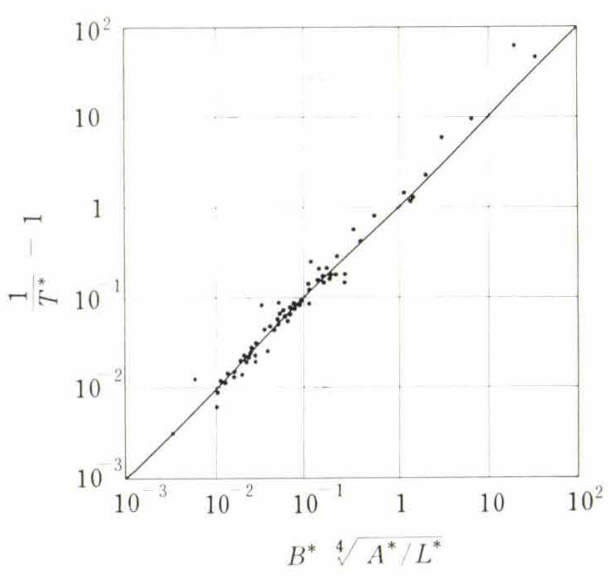

Fig. 4. The relation between the relative surface temperature $T^{*}=\left(\theta_{e}-\theta_{1}\right) /\left(\theta_{j}-\theta_{1}\right)$, the relative heat diffusivity $B^{*}=b_{1} / b_{2}$, the relative temperature diffusivity $A^{*}=\alpha_{1} / \alpha_{2}$, and the relative latent heat $L^{*}=L / c_{2}$ $\left(\theta_{,},-\theta_{1}\right)$ obtained from numerical calculations

tentative solution for this purpose and may be used for common metals cast in sand mold.

From Eq. (12), it is predicted that a large temperature drop is expected either when the heat diffusivity of the cast metal is small, e.g. iron, or when the heat diffusivity of the mold is large, e.g. metallic mold. In fact, if a metal is poured into a mold made of the same metal, $\theta_{e}$ will be half of $\theta_{f}$, because $B^{*}$ is unity. However, neither Eq. (12) nor (14) gives $\theta_{e}$ with a high accuracy for metal mold castings as indicated in Table 4 . In any case, the present method can not be applied to metal mold castings since air gap formation is neglected.

It is noted that in any of the above equations the decrease in surface temperature is independent of the casting size. This is because the temperature profiles in geometrically similar castings are similar to each other, though the time factors are much dependent on the size. Although there is an experimental report ${ }^{91}$ that the decrease in surface temperature during solidification of castings is dependent on the casting

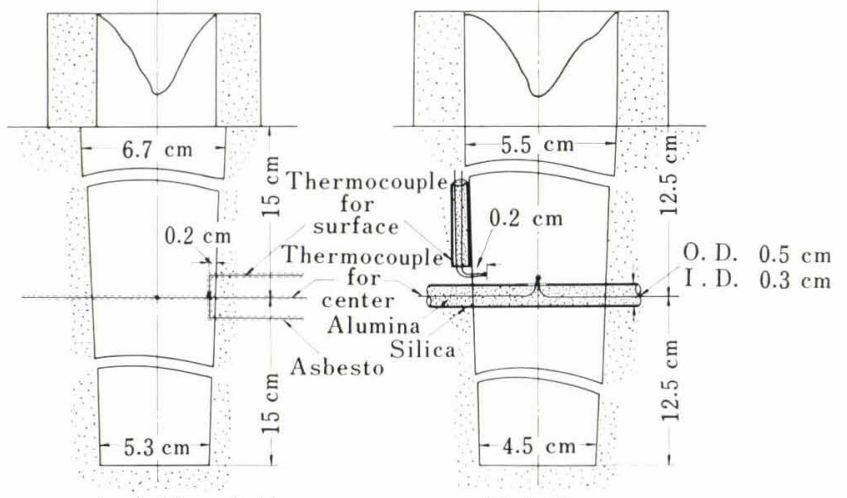

(a) $\mathrm{Pb}$ and $\mathrm{Al}$

(b) $\mathrm{Fe}$

Fig. 5. Experimental arrangement for temperature measurement

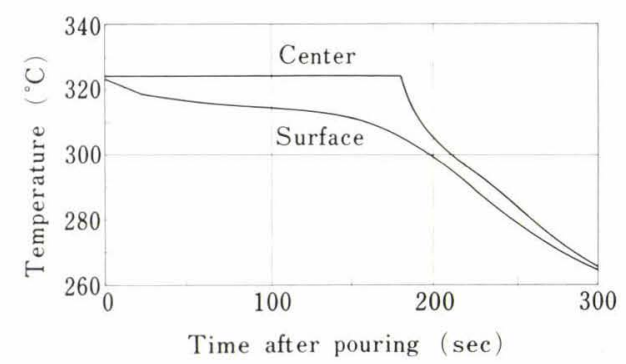

Fig. 6. An example of the temperature measurement on a lead casting poured in sand mold

size, it is suggested from the foregoing discussion that there could be some errors in the measurement.

\section{Examination of Experimental Data}

Cylindrical castings of lead, aluminum, and iron, one for each, were poured in sand molds, and the temperatures of the metal at the center and near the surface were recorded. The detail of the experimental procedures is shown in Fig. 5 and Table 5 . An example of the measurement is shown in Fig. 6, and the results are summerized in Table 6 .

As a result of the use of inaccurate thermal properties, the agreement between the experiment and the calculation is rather poor, particularly with respect to the solidification time. However, the order of magnitude of the measured temperature drop agrees well with the prediction. There is a reason to suspect that the measured temperature drop in iron was excessively large due to the influence of the temperature of the mold side of the interface.

For further confirmation, Pellini's data ${ }^{10,11)}$ were examined and the results are summerized in Table 7. Here again the comparison is not highly quantitative, since, besides the same reason mentioned above, the castings were square in section and alloys, instead of pure metals, were used in the experiment. Yet, the agreement with the prediction is fairly satisfactory.

Kondic's data, ${ }^{9}$ ' though on spheres, are also qualitatively in accordance with the present theory in that the temperature drop for iron is much larger than those for aluminum and copper. 
Table 5. Experimental procedures

\begin{tabular}{|c|c|c|c|c|}
\hline \multicolumn{2}{|c|}{ Cast metal } & $\mathrm{Pb}$ & $\mathrm{Al}$ & $\mathrm{Fe}$ \\
\hline \multicolumn{2}{|l|}{ Purity } & $99.99 \%$ & $99.9 \%$ & Electrolytic \\
\hline \multirow[t]{2}{*}{ Casting } & Diameter & $6 \mathrm{~cm}$ & $6 \mathrm{~cm}$ & $5 \mathrm{~cm}$ \\
\hline & Height & $30 \mathrm{~cm}$ & $30 \mathrm{~cm}$ & $25 \mathrm{~cm}$ \\
\hline \multirow[t]{3}{*}{ Riser } & Diameter & None & $6 \mathrm{~cm}$ & $5.5 \mathrm{~cm}$ \\
\hline & Height & & $6 \mathrm{~cm}$ & $5.5 \mathrm{~cm}$ \\
\hline & Treatment & & Pre-heat & $\begin{array}{l}\text { Pre-heat, exothermic } \\
\text { top cover }\end{array}$ \\
\hline \multicolumn{2}{|l|}{ Mold } & \multirow{2}{*}{\multicolumn{3}{|c|}{$\begin{array}{l}\text { Silica sand (Nikko No. } 5.5 \text { ) bonded } \\
\text { with } \mathrm{CO}_{2} \text { and dried at } 150^{\circ} \mathrm{C} \\
\text { Poured with no super-heat }\end{array}$}} \\
\hline \multicolumn{2}{|l|}{ l'ouring } & & & \\
\hline \multirow{4}{*}{$\begin{array}{l}\text { Thermo- } \\
\text { couple }\end{array}$} & Type & $\mathrm{CA}$ & CA & $\mathrm{Pt} / \mathrm{Pt}-13 \mathrm{Rh}$ \\
\hline & Diameter & $0.03 \mathrm{~cm}$ & $0.03 \mathrm{~cm}$ & $0.05 \mathrm{~cm}$ \\
\hline & $\begin{array}{l}\text { Lead } \\
\text { insulation }\end{array}$ & Asbesto & Asbesto & $\begin{array}{l}\text { Alumina powder in } \\
\text { silica tube }\end{array}$ \\
\hline & $\begin{array}{l}\text { Hot } \\
\text { junction } \\
\text { insulation }\end{array}$ & \multicolumn{3}{|c|}{$\begin{array}{l}\text { Thin coating with silica and zircon } \\
\text { powder }\end{array}$} \\
\hline
\end{tabular}

Table 6. Results of temperature measurements

\begin{tabular}{|c|c|c|c|c|c|c|c|}
\hline & \multicolumn{3}{|c|}{ Experiment } & \multicolumn{4}{|c|}{ Numerical calculation } \\
\hline & $\theta_{f}$ & $\theta_{f}-\theta_{e}$ & $t_{f}$ & $\theta_{f}$ & $\theta_{f}-\theta_{e}$ & $t_{f}$ & Mold \\
\hline $\mathrm{Pb}$ & 324 & 18 & 180 & 327 & 21 & 152 & A \\
\hline $\mathrm{Al}$ & 659 & 1 & 225 & 660 & 8 & 394 & A \\
\hline $\mathrm{Fe}$ & $\begin{array}{l}1537 \\
11530\end{array}$ & 138 & 90 & 1500 & 97 & 144 & G \\
\hline & & & & 1500 & 150 & 91 & $\mathrm{D}$ \\
\hline
\end{tabular}

Table 7. Comparison with the data by Pellini ${ }^{10,11}$

\begin{tabular}{|c|c|c|c|c|c|}
\hline \multirow{2}{*}{$\begin{array}{l}\text { Base } \\
\text { metal }\end{array}$} & \multirow{2}{*}{ Alloy } & \multicolumn{2}{|c|}{ Experiment } & \multicolumn{2}{|c|}{ Estimation } \\
\hline & & $\begin{array}{l}\text { Liquidus temp } \\
\qquad\left(\theta_{L}\right)\end{array}$ & $\theta_{L}-\theta_{e}$ & $\theta_{f}-\theta_{e}$ & Mold \\
\hline $\mathrm{Pb}$ & $\mathrm{Pb}$ & 324 & 30 & 18 & A \\
\hline \multirow[t]{3}{*}{$\mathrm{Fe}$} & $0.5 \% \mathrm{C}$ steel & 1477 & 50 & 100 & C \\
\hline & $12 \% \mathrm{Cr}$ steel & 1488 & 50 & 101 & $\mathrm{C}$ \\
\hline & 18-8 steel & 1449 & 55 & 99 & C \\
\hline $\mathrm{Ni}$ & Monel & 1335 & 40 & 64 & C \\
\hline \multirow[t]{3}{*}{$\mathrm{Al}$} & $\mathrm{Al}-8.5 \% \mathrm{Mg}$ & 602 & 0 & 7 & A \\
\hline & $\mathrm{Al}-4.5 \% \mathrm{Cu}$ & 643 & 0 & 8 & A \\
\hline & $\mathrm{Al}-7 \% \mathrm{Si}$ & 610 & 5 & 7 & A \\
\hline \multirow[t]{2}{*}{$\mathrm{Cu}$} & $\begin{array}{r}88-10-2 \\
\text { bronze }\end{array}$ & 1004 & 3 & 10 & B \\
\hline & $60-40$ brass & 896 & 15 & 9 & B \\
\hline
\end{tabular}

* Estimation was made from Eq. (14) by using $A^{*}, B^{*}$, and $L^{*}$ of the base metal and measured liquidus $\theta_{L}$ as $\theta_{f}$.

\section{Estimate of Solidification Time}

So far the surface temperature of cylindrical castings at the end of solidification has been discussed. To estimate the solidification time of the casting using
Table 8. Effect of surface temperature corrections on the calculated solidification time

\begin{tabular}{|c|c|c|c|c|c|c|}
\hline \multirow[b]{2}{*}{ Metal } & \multirow[b]{2}{*}{ Mold } & \multirow[b]{2}{*}{$B^{*}$} & \multicolumn{4}{|c|}{ Solidification time, $t_{f}$} \\
\hline & & & $\begin{array}{c}\text { Eq. (4) } \\
\text { Chvorinov }\end{array}$ & $\begin{array}{l}\text { Eq. (5) } \\
\text { Adams }\end{array}$ & $\begin{array}{l}\text { Cor- } \\
\text { rected } *\end{array}$ & $\begin{array}{l}\text { Numer- } \\
\text { ical } \\
\text { solution }\end{array}$ \\
\hline $\mathrm{Bi}$ & Sand A & 0.295 & $\begin{array}{c}6349 \\
(100 \%)\end{array}$ & $\begin{array}{c}4437 \\
(70 \%)\end{array}$ & $\begin{array}{c}6317 \\
(100 \%)\end{array}$ & $\begin{array}{c}6340 \\
(100 \%)\end{array}$ \\
\hline $\mathrm{Pb}$ & Sand A & 0.130 & $\begin{array}{c}1597 \\
(95 \%)\end{array}$ & $\begin{array}{r}1305 \\
(77 \%)\end{array}$ & $\begin{array}{l}1575 \\
(94 \%)\end{array}$ & $\begin{array}{c}1684 \\
(100 \%)\end{array}$ \\
\hline $\mathrm{Fe}$ & Sand D & 0.122 & $\begin{array}{c}922 \\
(63 \%)\end{array}$ & $\begin{array}{r}683 \\
(47 \%)\end{array}$ & $\begin{array}{c}1308 \\
(90 \%)\end{array}$ & $\begin{array}{c}1460 \\
(100 \%)\end{array}$ \\
\hline $\mathrm{Sn}$ & Sand A & 0.088 & $\begin{array}{c}8000 \\
(127 \%)\end{array}$ & $\begin{array}{r}5405 \\
(86 \%)\end{array}$ & $\begin{array}{l}5759 \\
(91 \%)\end{array}$ & $\begin{array}{c}6295 \\
(100 \%)\end{array}$ \\
\hline $\mathrm{Fe}$ & Sand $\mathrm{C}$ & 0.0825 & $\begin{array}{l}2024 \\
(88 \%)\end{array}$ & $\begin{array}{r}1450 \\
(63 \%)\end{array}$ & $\begin{array}{c}2308 \\
(100 \%)\end{array}$ & $\begin{array}{c}2310 \\
(100 \%)\end{array}$ \\
\hline $\mathrm{Ni}$ & Sand C & 0.0715 & $\begin{array}{c}3687 \\
(119 \%)\end{array}$ & $\begin{array}{c}2521 \\
(81 \%)\end{array}$ & $\begin{array}{c}3155 \\
(102 \%)\end{array}$ & $\begin{array}{c}3100 \\
(100 \%)\end{array}$ \\
\hline $\mathrm{Mg}$ & Sand A & 0.058 & $\begin{array}{c}2071 \\
(114 \%)\end{array}$ & $\begin{array}{c}1652 \\
(91 \%)\end{array}$ & $\begin{array}{c}1785 \\
(99 \%)\end{array}$ & $\begin{array}{c}1810 \\
(100 \%)\end{array}$ \\
\hline $\mathrm{Zn}$ & Sand A & 0.054 & $\begin{array}{c}8003 \\
(146 \%)\end{array}$ & $\begin{array}{r}5408 \\
(98 \%)\end{array}$ & $\begin{array}{c}5706 \\
(104 \%)\end{array}$ & $\begin{array}{c}5495 \\
(100 \%)\end{array}$ \\
\hline $\mathrm{Al}$ & Sand A & 0.038 & $\begin{array}{c}5841 \\
(133 \%)\end{array}$ & $\begin{array}{r}4130 \\
(94 \%)\end{array}$ & $\begin{array}{l}4281 \\
(98 \%)\end{array}$ & $\begin{array}{c}4380 \\
(100 \%)\end{array}$ \\
\hline $\mathrm{Cu}$ & Sand B & 0.027 & $\begin{array}{c}4692 \\
(139 \%)\end{array}$ & $\begin{array}{r}3285 \\
(97 \%)\end{array}$ & $\begin{array}{c}3424 \\
(101 \%)\end{array}$ & $\begin{array}{c}3380 \\
(100 \%)\end{array}$ \\
\hline
\end{tabular}

* Correction was made by Eqs. (14), (15), (16), and (5).

Adams' equation, one must first know the average temperature over the entire section of the casting at the end of solidification and the effective mean surface temperature of the mold from the start to the end of solidification. Since the latter is of less importance, a satisfactory result may be obtained with a simple formula

$$
\theta_{m}=0.5 \times\left(\theta_{f}+\theta_{e}\right) \ldots
$$

For the former, the numerical results were examined and the following approximate relationship was established.

$$
\theta_{a}=0.2 \times \theta_{f}+0.8 \times \theta_{e}
$$

This becomes as the exact solution, when the temperature drop from the melting point at any location is proportional to the square root of the distance from the center.

Now the procedure to obtain the solidification time is as follows. The value of $\theta_{e}$ is obtained from Eq. (12) or, preferably by Eq. (14). Then, $\theta_{m}$ and $\theta_{a}$ are obtained by putting $\theta_{e}$ into Eqs. (15) and (16). The value of $q$ is obtained by replacing $\theta_{i}$ in Eqs. (6) and (5) by $\theta_{m}$ and $\theta_{f}$ by $\theta_{a}$. Finally $t_{f}$ is obtained from Eq. (1).

Some examples are shown in Table 8. It is demonstrated that for metals with low heat diffusivity, Chvorinov's equation gives a better approximation than Adams', if no corrections are made. For metals with high heat diffusivity, Adams' equation is better than Chvorinov's. If the corrections with respect to the decrease in surface temperature are made to Adams' equation, consistently reliable results are obtained. 


\section{Significance of Surface Temperature Cor- rections on Riser Designing}

The most important factor in determining the size of riser is the solidification time relative to that of the casting. It has been shown in the foregoing that the solidification time can be calculated from Eq. (2), provided that $K$ is considered as a function not only of the thermal properties but also of the geometry of the casting. If a cylindrical riser is attached to a plate casting, $K$ for a cylinder and $K$ for a plate, or at least their ratio, must be known. Using the thermal properties listed in Table 2, the values of $K$ were calculated for a few examples and are shown in Table 9 .

For copper, the value of $K$ for a cylinder is much smaller than that for a plate. This is resulted from the corner effect. For iron poured in normal sand, the value of $K$ for a cylinder is nearly equal to that for a plate. For iron poured in high diffusivity mold, the value of $K$ for a cylinder is large than that for a plate. This happens because the decrease in surface temperature during solidification of the cylinder is so large as to overcome the corner effect of the mold. This seems to be a more reasonable interpretation of Pellini's data ${ }^{2)}$ than the earlier one by Ruddle. ${ }^{4)}$

It is sufficient in the present paper to point out the dependence of $K$ on the casting geometry even in iron or steel, depending on the mold thermal properties. The accurate values of $K$ are best to be obtained from direct measurement of the solidification time, because the figures in Table 9 are based only on the approximate values of the thermal properties and, in fact, in most cases the precise properties are not known. Once $K$ is obtained for a given shape and a combination of metal and mold, it can be used for any size.

\section{Conclusions}

In an attempt to improve the precision of Chvorinov's equation, validity of the assumption of constant surface temperature was examined by means of numerical calculations with a few additional experiments and the following conclusions were obtained.

(1) The surface temperature of a cylindrical casting immediately after pouring is equal to that of a plate casting, which is somewhat lower than the melting point. The temperature decreases gradually, unlike a plate, and, hence, the surface temperature at the end of solidification is more or less lower than the starting temperature.

(2) The decrease in temperature defined as the difference between the melting point and the temperature at the end of solidification, depends mainly on the relative heat diffusivity, the ratio of heat diffusivity of the mold to that of the cast metal. It also depends on the relative temperature diffusivity and the relative latent heat. A formula was proposed to estimate the decrease in temperature in a given metal and mold.

(3) In the case of metals, like copper or aluminum, whose heat diffusivity is large, the decrease in surface
Table 9. Some examples of Chvorinov's constant $K$ as calculated numerically for plates and cylinders

\begin{tabular}{lclrc} 
Metal** & Mold** & Shape & $K^{*}$ & $\begin{array}{c}\text { Temp. drop } \\
\theta_{f}-\theta_{e}\end{array}$ \\
\hline Copper & B & Plate & 187 & 0 \\
Copper & B & Cylinder & 148 & 7 \\
Iron & C & Plate & 94 & 24 \\
Iron & C & Cylinder & 92 & 97 \\
Iron & D & Plate & 47 & 54 \\
Iron & D & Cylindr & 58 & 150
\end{tabular}

* $\quad K$ in Eq. (2), $\sec / \mathrm{cm}^{2}$.

** Thermal properties are listed in Table 2 .

temperature is so small that it can be neglected in calculating the solidification time. Adams' equation, instead of Chovorinov's, should be used for cylinders of such metals.

(4) In the case of metals like iron, steel, or lead, whose heat diffusivity is small, the decrease in surface temperature is large and Adams' equation gives a satisfactory value only if necessary corrections are made to the temperature terms. Chvorinov's equation can be a good approximation for cylindrical steel castings poured in normal sand, due to a fortuitous mutual cancelling of two inaccurate assumptions, namely, the constant surface temperature and the neglect of ' corner' effect.

(5) In steel casting poured in high diffusivity mold, it is possible that the effect of the decrease in surface temperature overcomes the corner effect with the result that the solidification time of a cylinder is longer than that of a plate having the same ratio of volume to surface area.

(6) It is desirable to establish experimentally the constant $K$ for various casting shapes and combinations of metals and molds. This will be of particular value for steel castings in various types of molding sands.

\section{REFERENCES}

1) N. Chvorinov: Giesserei, 27 (1940), 10, 177, 201.

2) W. S. Pellini: Trans. AFS, 61 (1953), 603.

3) C. M. Adams and H. F. Taylor: Trans. AFS, 65 (1957), 170.

4) R. W. Ruddle: The Solidification of Castings, (1957), Institute of Metals.

5) G. M. Dusinberre: Heat-Transfer Calculations by Finite Differences, (1961), International Textbook Co.

6) L. R. Ingersoll, O.J. Zobel, and A. C. Ingersoll: Heat Conduction, (1954), 91, Univ. Wisconsin Press.

7) H. S. Carslaw and J. C. Jaeger: Conduction of Heat in Solids, (1959), 285, Oxford.

8) W. H. McAdams: Heat Transmission, (1954), 192, McGraw-Hill.

9) J. Berry, V. Kondic, and G. Martin: Trans. AFS, 67 (1959), 449.

10) H. F. Bishop, F. A. Brandt, and W. S. Pellini: Trans. AFS, 59 (1951), 435.

11) F. A. Brandt, H. F. Bishop, and W. S. Pellini: Trans. AFS, 62 (1954), 646 , 